\title{
Oral Azacitidine
}

National Cancer Institute

\section{Source}

National Cancer Institute. Oral Azacitidine. NCI Thesaurus. Code C118288.

An orally bioavailable formulation of azacitidine, a pyrimidine nucleoside analogue of cytidine, with antineo plastic activity. Upon oral administration, azacitidine is taken up by cells and metabolized to 5-azadeoxycitidine triphosphate. The incorporation of 5azadeoxycitidine triphosphate into DNA reversibly inhibits DNA methyltransferase, and blocks DNA methylation. Hypomethylation of DNA by azacitidine may re-activate tumor suppressor genes previously silenced by hypermethylation, resulting in an antitumor effect. In addition, the incorporation of 5-azacitidine triphosphate into RNA disrupts normal RNA function and impairs tRNA (cytosine-5)-methyltransferase activity, resulting in an inhibition of RNA and protein synthesis. 